\title{
Evaluation of the Effect of Outdated Drugs for Treatment of COVID-19
}

\author{
Ali Ahmadi* \\ Department of Biological Sciences and Technologies, Islamic Azad University, Iran
}

\section{LETTER TO EDITOR}

\section{Dear Editor,}

Chloroquine (CQ) is considered as a drug that has been significantly motivated versus malaria and observed in 2006 that this drug has an antimicrobial potential for the mechanism and chloroquine function increases the $\mathrm{pH}$ of the endosomal [1]. With a higher $\mathrm{pH}$ of what is required for virus/cell fusion, it blocks the infection and prevents the progression of the disease. This is due to the SARS-COV-2 cellular receptor glycoproteins that are connected to their items [2]. But the hydroxy chloroquine can inhibit the stage before the cellular binding in the cell surface receptor, in a study in a study by a group of Chinese researchers and scientists about the efficiency and function of chloroquine Laboratory studies have been carried out using VERO E6 cells infected with SARSCOV-2 in polyethylene infection (MOI) 0.05 , chloroquine has been very effective in reducing the virus and has an impressive effect and can infect SARS-COV- 2 block at low concentrations (effective concentration of maximum (EC50) $1.13 \mu \mathrm{m}$ and the concentration of semi-cytotoxicity (CC50) larger than $100 \mu \mathrm{m}$ ). Another article showed that chloroquine could prevent the proliferation of HCOV$229 \mathrm{E}$ in laboratory conditions in the culture of lung epithelial cells and can also be effective against the Coronavirus of the Middle East Respiratory Syndrome (Mers-Cov) in laboratory conditions. Hydroxy chloroquine (HCQ) with a very similar chemical structure with chloroquine is one of the moderating diseases of anti-rheumatic drugs used to treat many [3]. The use of this lopinavir and raravir, which actually produced to deal with the AIDS virus, has also not affected the status of citizens with corona. The experiments showed that these drugs, which are usually sold by Kaltra, have reduced the mortality rate caused by Corona, rather than the risk of sub-oxygen. This treatmentmethod has noteven shorter patient's hospitalization. In another study, anti-HIV drugs, lopinavir and paint, may have a therapeutic effect on Covid-19 disease [3]. This means that the therapeutic effect of Ritonavir and Lopinavir on Covid-19 may be largely due to its inhibitory effect on CEP_C30 of the corona virus, while Ritonavir may have more ability and performance, the inhibitory effect of Darney on SARS-COV-2 and the effect of its potential therapeutic therapy may be largely due to its inhibitory effect on PLVP (peptic viral protease) [1]. Lopinavir is metabolized by cytochrome P4503A (CYP3A) in the liver. This drug is always used with Ritonavir to reduce the dose of lopinavir and increase the level of lopinavir in plasma because Ritonavir prevents the Isoenzyme CYP3A. Lopinavir and Ritonavir viral protease inhibitors have been selected as the second line for the treatment of HIV-1 infection in children and adults with lower side effects with lower side effects of steroids and hospital infections in patients initially treated with Lopinavir/Ritonavir They have been observed, also, the results indicate a reduction in viral load and increase the number of peripheral lymphocytes. The findings of laboratory and clinical studies, along with the specifications of the availability and immunity of Lopinavir/Ritonavir and interferon beta 1b (IFN$\beta 1 \mathrm{~b})$, show that the combination of these factors to treat patients with Mers-Cov has a potential effect. The question of whether the previous approach of Lopinavir-Ritonavir in Covid-19 can have clinical benefits, is an important issue that requires more study. A new report showed that the average duration of virus release in COVID-19 in patients with severe illness was 20 days and can also take up to 37 days. There is no proven evidence that LopinavirRitonavir has a significant antiviral effect [4].

\section{REFERENCES}

1. Barati F, Mahdi P, Elena E, Sahar A, Farzad RZ, et al. (2020) Potential drugs and remedies for the treatment of COVID-19: A critical review. Biological Procedures Online 22(1): 1-17.

2. Damle B, Manoli V, Erjian W, Joanne L, Brian C, et al. (2020) Clinical pharmacology perspectives on the antiviral activity of azithromycin and use in COVID-19. Clinical Pharmacology \& Therapeutics 108(2): 201211.

3. Zambrano MA, Ruano MA, Sanchez AL (2020) Indirect effects of COVID-19 on the environment. Science of the Total Environment 728: 138813.

4. Zheng S, Li Y, Peng XZ, Hui-Bo L, Fang L, et al. (2021) Recommendations and guidance for providing pharmaceutical care services during COVID-19 pandemic: A China perspective. Research in Social and Administrative Pharmacy 17(1): 1819-1824.
Quick Response Code:

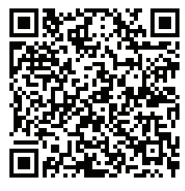

Address for correspondence: Ali Ahmadi, Department of Biological Sciences and Technologies, Islamic Azad University, Iran

Received: October 05, 2021

Published: October 18, 2021

How to cite this article: Ali A. Evaluation of the Effect of Outdated Drugs for Treatment of COVID-19. 2021- 3(5) OAJBS.ID.000335. DOI: 10.38125/OAJBS.000335 